\title{
EDITORIALS
}

\section{In the Shadow of Iraq: Posttraumatic Stress Disorder in 2007}

\author{
David L. Greenburg, MD, MPH and Michael J. Roy, MD, MPH \\ Department of Medicine, Uniformed Services University, Room A3062, 4301 Jones Bridge Road, Bethesda, MD 20814, USA.
}

DOI: $10.1007 / \mathrm{s} 11606-007-0172-\mathrm{x}$

(C) 2007 Society of General Internal Medicine 2007;22:888-889

I raq has become a more effective incubator for posttraumatic stress disorder (PTSD) in the American service members than any mad scientist could conceivably design. The combat zone in Iraq has no frontline, no safe zone, and the embattled soldier has little with which to differentiate friend from foe, no warning of when or where the next improvised explosive device will be detonated. It is hardly surprising that we are seeing high rates of depression, PTSD, and other anxiety disorders in service members who have been deployed to Iraq. ${ }^{1}$ The moniker of PTSD was established in a similar war environment, Vietnam, but the condition has been present for as long as men have fought wars over religion, ethnicity, land, or greed. Homer's saga of Achilles in The Iliad represents perhaps the oldest detailed account of the ravages of PTSD in the soldier, a portrayal vividly dissected by psychiatrist Jonathan Shay. ${ }^{2}$

PTSD and depression are by no means unique to combat veterans-they are common in the primary care setting, where they are underdiagnosed and undertreated. ${ }^{3}$ There are a variety of reasons for this. Five of six primary care patients with a chief complaint ultimately attributed to a mental disorder present with a somatic complaint, invariably obfuscating the diagnosis. ${ }^{4}$ Primary care physicians have a myriad of other issues to deal with in their patients, including diabetes, hyperlipidemia, and hypertension, all featuring discrete numbers that demand attention. Patients with mental disorders also fear stigmatization and tend to minimize psychological symptoms. However, the advent of relatively safe, well-tolerated, and effective selective serotonin reuptake inhibitors put effective treatment modalities in the hands of primary care physicians, and manufacturers' direct-toconsumer advertisements have helped to overcome stigma. Of equal importance, the development and validation of the Patient Health Questionnaire-9 (PHQ-9) provide physicians with an effective tool to diagnose depression and a score to gauge responsiveness to interventions. ${ }^{5}$ Unfortunately, there is no similarly effective instrument for PTSD, and whereas there are effective treatments available, pharmacotherapy does not seem to be quite as facile for PTSD as for depression. Thus, it is not a great surprise that Liebschutz et al. ${ }^{6}$ found

Published online March 21, 2007
PTSD was rarely diagnosed (identified in the medical record for only $11 \%$ of those meeting criteria) in an urban primary care population, reported in this issue of Journal of General Internal Medicine. Misdiagnosis was commonplace, with a diagnosis of depression recorded for $43 \%$ of those who met the criteria for PTSD but not depression. PTSD was also three times more common (adjusted prevalence 35\%) in those who did have depression in this population of predominantly poor, inner city, unmarried African Americans than those who did not (11\%). Nearly identical depression-PTSD comorbidity rates were identified by Campbell et al., ${ }^{7}$ also in this issue, in predominantly older white males receiving primary care at Veterans Administration facilities; similar rates have been reported elsewhere. ${ }^{8,9}$ Whereas the comorbidity appears compelling, these are both cross-sectional studies, so it is impossible to say which condition developed first. Moreover, as Liebschutz et al. demonstrate, this relationship is hardly unique to depression; those with other anxiety disorders also had three times the rate of PTSD, and those with chronic pain or irritable bowel syndrome each had twice the rate of PTSD as those who did not. Because the overall prevalence of PTSD in this inner city population was $23 \%$, a cogent argument can be made to screen all comers for PTSD, rather than trying to target those at even greater risk, but the cost-effectiveness of each approach should be assessed.

The problem that primary care physicians then face is what instrument should they use to screen for PTSD? The Clinician Administered PTSD Scale is the gold standard, but its 17-page length, detailed instructions, and complex scoring render it impractical for use in primary care. The 17-item PTSD Checklist has a scoring mechanism similar to the PHQ-9, but had a sensitivity of only $32 \%$ among 400 primary care patients. ${ }^{10} \mathrm{~A}$ 7 -item scale was reported to moderate sensitivity $(85 \%)$ and specificity $(84 \%)$ in 134 primary care patients, but requires confirmation in larger studies. ${ }^{11}$ Campbell et al. opted for the PC-PTSD, a 4-item Primary Care PTSD screen, based upon a prior study in 188 VA patients that identified an optimal cutoff score of three positives out of the four items. However, a more recent, larger study yielded a sensitivity of only $46 \%$ at this threshold in 690 OIF/OEF veterans, whereas a threshold of two had a sensitivity of $73 \%$ with a specificity of $86 \% .^{12}$ Additional research is necessary to determine the optimal brief screen for PTSD.

Identification of PTSD is important because it is associated with markedly higher rates of depression and other psychological conditions, poorer physical health, unemployment and missed work, impaired function at work and at home, and significantly higher health care costs. ${ }^{13}$ Moreover, the combination of PTSD and depression is linked to greater depression 
severity and duration, as well as physical complaints and functional impairment, ${ }^{9,14}$ so diagnosing PTSD in those with depression would seem particularly important. Unfortunately, as noted by Campbell et al., whereas the Department of Defense/Veterans Administration practice guidelines, and a plethora of others, address the separate conditions of PTSD and depression, none address the combination. This should be redressed. Whereas it is presumed that improving practice guidelines, and increasing diagnostic rates for PTSD, would improve treatment rates and health outcomes, this is another area where further research is needed.

Expert panels confirmed exposure therapy as the bestevidenced therapy for PTSD after a meta-analysis identified an effect size of 1.17 compared to 0.69 for pharmacotherapy, and mean dropout rates of $32 \%$ for pharmacotherapy versus $14 \%$ for psychotherapy. ${ }^{15}$ Exposure therapy begins with the use of cognitive behavioral techniques, and then usually relies on the patient to repeatedly recount, in as vivid detail as possible, all recollections of his/her traumatic experiences. The therapist uses these memories to help the patient work through and reduce symptoms associated with them, a process known as imaginal exposure. However, avoidance of reminders of the trauma is a defining feature of PTSD, so many are unable or unwilling to engage. Recently, several small studies have indicated that the use of virtual reality to facilitate multisensory stimulatory recall of trauma may be particularly powerful. ${ }^{16-18}$ Larger, better-controlled studies are currently underway, including some treating veterans from Iraq; if successful, these may revolutionize our approach to PTSD.

Whereas the situation in Iraq seems to yield only the most sour of lemons, there are many who seek to make the sweetest of lemonade. The National Institute of Mental Health, the U.S. Army Medical Research and Materiel Command, and other funding agencies are being inundated with innovative, thoughtful proposals to improve the diagnosis of PTSD, and it is regrettable that current levels of funding enable them to sponsor only a small fraction of the submissions they receive. Every war our nation has fought has led to significant medical advances that benefit not only the service members, but society at large. The legacies of the current war, already the longest continuous combat operations for an all-volunteer U.S. force since the fight for independence from Great Britain more than 200 years ago, will include (1) the value of body armor, sharply limiting the number of severe thoracic and abdominal injuries, and consequently increasing the percentage of limb injuries; (2) the flying intensive care unit, making it possible to whisk the sickest of soldiers across the globe to a safe site for definitive care; and (3) marked advances in prosthetic limbs and the care of amputees. We hope that it will 1 day be possible to add significant advances in the diagnosis and treatment of PTSD to this list.
Acknowledgement: The opinions expressed in this paper are those of the authors and should not be construed in any way to represent those of the U.S. Army or the Department of Defense.

Corresponding Author: Michael J. Roy, MD, MPH; Department of Medicine, Uniformed Services University, Room A3062, 4301 Jones Bridge Road, Bethesda, MD 20814, USA (e-mail: mroy@usuhs.mil).

\section{REFERENCES}

1. Hoge CW, Castro CA, Messer SC, McGurk D, Cotting DI, Koffman RL. Combat duty in Iraq and Afghanistan, mental health problems, and barriers to care. N Engl J Med. 2004;351:13-22.

2. Shay J. Achilles in Vietnam: Combat Stress and the Undoing of Character. New York: Scribner; 1995.

3. Hirschfeld RM, Keller MV, Panico S, et al. The National Depressive and Manic-Depressive Association consensus statement on the undertreatment of depression. JAMA. 1997;277:333-40.

4. Bridges KW, Goldberg G. Somatic presentation of DSM III psychiatric disorders in primary care. J Psychosom Res. 1985;29:653-9.

5. Kroenke K, Spitzer RL, Williams JBW. The PHQ-9. J Gen Intern Med. 2001;16:606-13.

6. Liebschutz J, Saitz R, Brower V, et al. PTSD in urban primary care: high prevalence and low physician recognition. J Gen Intern Med. DOI:10.1007/ s11606-007-0161-0.

7. Campbell DG, Felker BL, Liu CF, et al. Prevalence of depressionPTSD comorbidity: implications for clinical practice guidelines and primary care-based interventions. J Gen Intern Med. DOI:10.1007/ s11606-006-0101-4.

8. Kessler R, Sonega A, Bromet E, Hughes M, Nelson C. Posttraumatic stress disorder in the National Comorbidity Survey. Arch Gen Psychiatry. 1995;52:1048-60.

9. Green BL, Krupnick JL, Chung J, et al. Impact of PTSD comorbidity on one-year outcomes in a depression trial. J Clin Psychol. 2006;62: 815-35.

10. Stein MB, McQuaid JR, Pedrelli P, Lenox R, McCahill ME. Posttraumatic stress disorder in the primary care medical setting. Gen Hosp Psychiatry. 2000;22:261-9.

11. Kimerling R, Ouimette $\mathbf{P}$, Prins A, et al. Brief report: utility of a short screening scale for DSM-IV PTSD in primary care. J Gen Intern Med. 2006;21:65-7.

12. Bliese PD, Wright KM, Adler AB, Thomas JL. Psychological screening validation with soldiers returning from combat. In: Roy MJ, ed. Novel Approaches to the Diagnosis and Treatment of Posttraumatic Stress Disorder. Amsterdam: IOS Press; 2006.

13. Kessler RC. Posttraumatic stress disorder: the burden to the individual and to society. J Clin Psychiatry. 2000;61(suppl 5):4-14.

14. Frayne SM, Seaver MR, Loveland S, et al. Burden of medical illness in women with depression and posttraumatic stress disorder. Arch Intern Med. 2004;164:1306-12.

15. Van Etten ML, Taylor S. Comparative efficacy of treatments for PTSD: a meta-analysis. Clin Psychol Psychother. 1998;5:126-45.

16. Rothbaum BO, Hodges LF, Ready D, Graap K, Alarcon RD. Virtual reality exposure therapy for Vietnam veterans with posttraumatic stress disorder. J Clin Psychiatry. 2001;62:617-22.

17. Difede J, Cukor J, Patt I, Giosan C, Hoffman H. The application of virtual reality to the treatment of PTSD following the WTC attack. Ann N Y Acad Sci. 2006;1071:500-1.

18. Beck JG, Palyo SA, Winer EH, Schwagler BE, Ang EJ. Virtual reality exposure therapy for PTSD symptoms after a road accident: an uncontrolled case series. Behav Ther. 2007;38:39-48. 